Research Paper

\title{
Prostanoids counterbalance the synergism between endothelin- 1 and angiotensin II in mesenteric veins of trained rats
}

\author{
Agnaldo Bruno Chies ${ }^{\mathrm{a}, *}$, Priscilla Bianca de Oliveira ${ }^{a}$, Patrícia de Souza Rossignoli ${ }^{\mathrm{b}}$, \\ Rafaela de Fátima Ferreira Baptista ${ }^{\mathrm{c}, \mathrm{d}}$, Roger William de Lábio ${ }^{\mathrm{e}}$, \\ Spencer Luiz Marques Payão ${ }^{\mathrm{e}}$ \\ a Laboratory of Pharmacology, Marília Medical School, SP, Brazil \\ ${ }^{\mathrm{b}}$ Department of Physiotherapy and Occupational Therapy, São Paulo State University (UNESP), Marília, SP, Brazil \\ ${ }^{\mathrm{c}}$ Faculty Esefap of Tupã, SP, Brazil \\ ${ }^{\mathrm{d}}$ Faculty of Alta Paulista (FAP), Tupã, SP, Brazil \\ e Laboratory of Genetic, Marília Medical School, São Paulo, Brazil
}

\section{A R T I C L E I N F O}

\section{Article history:}

Received 19 July 2016

Received in revised form

15 December 2016

Accepted 20 December 2016

Available online 21 December 2016

\section{Keywords:}

Angiotensin II

Endothelin-1

Exercise

Nitric oxide

Prostanoids

Vein

\begin{abstract}
A B S T R A C T
Exercise-induced adaptations of the modulating mechanisms that influence the angiotensin (Ang II) responses assume different features depending on the venous bed. In femoral veins, exercise mobilizes vasodilator prostanoids to cooperate with $\mathrm{NO}$ in order to maintain reduced Ang II responses. On the other hand, exercise's influence on the Ang II responses in veins that drain blood from the mesenteric region has been poorly described. Therefore, the present study aimed to identify the effects of a single bout of exercise, as well as exercise training, on the Ang II responses in mesenteric veins. The present study also aimed to investigate the involvement of prostanoids, NO and ET- 1 in eventual exercise-induced modifications in these veins. To this end, mesenteric veins taken from resting-sedentary, exercised-sedentary, resting-trained and exercised-trained animals were studied in organ baths. In addition, the mRNA expression of prepro-endothelin-1 (ppET-1), as well as that of the $\mathrm{ET}_{\mathrm{A}}$ and $\mathrm{ET}_{\mathrm{B}}$ receptors, were quantified by real-time PCR in these veins. The results show that, either in absence or in presence of L-NAME, the Ang II responses were not different between groups. In the presence of indomethacin, higher Ang II responses were observed in the resting-trained animals than in the resting-sedentary animals. This difference, however, disappeared when L-NAME, BQ-123 or BQ-788 were added during incubation. In addition, no differences in ppET-1, $\mathrm{ET}_{\mathrm{A}}$ or $\mathrm{ET}_{\mathrm{B}}$ mRNA expression were observed between groups. Furthermore, in the presence of PD123,319, the Ang II responses in the exercised-sedentary animals were higher than those in the resting-sedentary animals. In conclusion, exercise training mobilizes endothelin-1 (ET-1) to reinforce the Ang II-induced responses mainly through $\mathrm{ET}_{\mathrm{A}}$ activation. On the other hand, vasodilator prostanoids are mobilized to act in parallel with NO in order to counterbalance the Ang II responses that have been potentiated by ET-1 in these trained animals.
\end{abstract}

(c) 2016 Elsevier Inc. All rights reserved.

\section{Introduction}

The renin-angiotensin system (RAS) may participate in the active modification of vascular tonus, thereby contributing to exercise-induced circulatory redistribution [1]. In order to exert this role, the RAS may work independently or in association with the sympathetic nervous system [2]. The RAS controls vascular tonus through their effectors, among which angiotensin II (Ang II)

\footnotetext{
* Corresponding author at: Laboratory of Pharmacology, Marília Medical School, Av. Monte Carmelo, 800, Fragata, 17 519-030, Marília, SP, Brazil.

E-mail address: agnaldochies@hotmail.com (A.B. Chies).
}

is one of the most important. However, depending on the vascular territory, Ang II responses may be modulated by other local mediators such as prostanoids, nitric oxide (NO) and endothelin-1 (ET-1) [3-5]. These local mediators may modulate Ang II responses not only in arteries but also in veins. However, these local mechanisms are currently better understood in the arterial bed than they are in the venous bed.

The modulating mechanisms that influence Ang II responses may be modified by exercise. However, in the venous bed, such exercise-induced adaptations may assume different features depending on territory. For example, Ang II responses are changed by exercise exposition in the portal vein, but not in the vena cava [6]. It was also observed that a single bout of exercise, as well as exercise 
training, mobilize vasodilator prostanoids to cooperate with NO in order to maintain reduced Ang II responses in femoral veins [7]. Notably, femoral veins mobilize blood flow from the musculocutaneous territory where the absence of appreciable venoconstriction may actually be beneficial because it impedes an uncontrolled increase in the resistance to centripetal flow [8]. On the other hand, little is known about the influence of acute and/or repeated exercise exposition on the Ang II responses in veins that drain blood from the mesenteric region. This lack of knowledge limits our understanding of the physiology of venous return because there is a relative consensus that active vasoconstriction in the mesenteric territory contributes to blood mobilization during exercise.

Therefore, the present study aimed to identify the effects of a single bout of exercise, as well as exercise training, on the Ang II responses in mesenteric veins. It also aimed to investigate the involvement of prostanoids, NO and ET-1 in eventual exerciseinduced modifications of contractile responses evoked by Ang II in these veins.

\section{Material and methods}

\subsection{Animals}

One hundred forty-six male Wistar rats (350-450 g) were housed in plastic cages $(50 \times 40 \times 20 \mathrm{~cm})$ with five animals per cage. Food and water were available ad libitum. During the exercise protocol, rats were maintained in the training room under a $12 \mathrm{~h}$ light-dark cycle, with lights on at 07:00 h. Room temperature was maintained at $25^{\circ} \mathrm{C}$.This study was approved by the Research Ethics Committee of Marilia Medical School (Protocol n ${ }^{\circ}$ 351/09).

\subsection{Exercise protocol}

The exercise protocol used was based on a previous study [9]. In short, the animals were subjected to the maximal exercise test on a treadmill (Movement Technology LX 170) to determine their ability to run on the treadmill. Based on the results of this test, the animals were randomly assigned to sedentary or trained groups with a similar average of maximal exercise capacity in both groups. Then, the animals designated as trained were exercised 5 days per week for $1 \mathrm{~h}$ per day for 10 weeks. The exercise intensity was progressively increased by a combination of time and velocity, attaining $1 \mathrm{~h}$ per day at a velocity correspondent to $60 \%$ of maximal exercise by the third week. This protocol has been defined as constituting low-intensity exercise training $[9,10]$. All of the animals used in the present study increased their maximal exercise capacity from the first to the sixth week, when the maximal exercise tests were repeated. This improvement of exercise conditioning was considered an indirect indication of the efficacy of the exercise training.

Two groups of sedentary and two groups of trained animals were subjected in parallel to organ bath experiments or mesenteric veins samples harvest (for RNA analysis through Real-time PCR). One group of sedentary and one group of trained animals, designated respectively as resting-sedentary and resting-trained, were submitted to these procedures at rest. The other two groups of sedentary and trained animals, designated respectively as exercised-sedentary and exercised-trained, underwent a bout of exercise immediately before the organ bath experiments/samples harvest. Notably, the resting-sedentary animals were submitted to shorter bouts of exercise (15 $\mathrm{min})$.

\subsection{Organ bath studies}

Animals were killed in a $\mathrm{CO}_{2}$ chamber and exsanguinated. The mesenteric veins (3-4 mm; two rings per animal) were prepared and set up in $2 \mathrm{~mL}$ organ baths. Rings were fixed to a stainlesssteel hook attached to a stationary support, as well as to a hook connected to an isometric force transducer. Rings were bathed in Krebs-Henseleit solution (composition in mmol/L): ( $\mathrm{NaCl} 130 ; \mathrm{KCl}$ 4.7; $\mathrm{CaCl}_{2}$ 1.6; $\mathrm{KH}_{2} \mathrm{PO}_{4} 1.2 ; \mathrm{MgSO}_{4} 1.2 ; \mathrm{NaHCO}_{3}$ 15; glucose 11.1). The solution was kept at pH 7.4 and $37^{\circ} \mathrm{C}$ and bubbled continuously with a mixture of $95 \% \mathrm{O}_{2}$ and $5 \% \mathrm{CO}_{2}$. Tension was monitored continuously and recorded using a force transducer $(5 \mathrm{mg}-25 \mathrm{~g})$ coupled to a Powerlab 8/30 data-acquisition system (ADInstruments, Castle Hill, NSW, Australia). Prior to administering drugs, rings were equilibrated for $60 \mathrm{~min}$ at a resting tension of $0.5 \mathrm{~g}$. The time frame from the end of the exercise bouts to the beginning of the Ang II cumulative concentration-response curves was approximately $90 \mathrm{~min}$.

The responses ( $\mathrm{g}$ ) evoked by cumulatively adding Ang II $\left(10^{-11} \mathrm{M}\right.$ to $10^{-7} \mathrm{M}$; Sigma) directly into the organ bath were plotted to obtain concentration-response curves. The actions of Ang II were also evaluated in pretreated rings for $20 \mathrm{~min}$ with $10^{-4} \mathrm{~mol} / \mathrm{L} \mathrm{L}-\mathrm{NAME}$ and/or $10^{-5} \mathrm{~mol} / \mathrm{L}$ indomethacin, non-selective nitric oxide synthase and cyclooxygenase inhibitors (Sigma), respectively. Some mesenteric veins were also studied in the presence of $10^{-5} \mathrm{~mol} / \mathrm{L}$ indomethacin plus $10^{-6} \mathrm{~mol} / \mathrm{L} \mathrm{BQ}-123$ (antagonist of endothelin receptor type $A-E_{A}$; Sigma) or $10^{-6} \mathrm{~mol} / \mathrm{L} \mathrm{BQ}-788$ (antagonist of endothelin receptor type $\mathrm{B}-\mathrm{ET}_{\mathrm{B}}$; Sigma). Mesenteric veins were also challenged with Ang II in the presence of $10^{-6} \mathrm{~mol} / \mathrm{L}$ PD123,319 (antagonist of $\mathrm{AT}_{2}$ receptors - $\mathrm{AT}_{2}$ ). All drugs were administered directly to the organ bath. Non-linear regressions (variable slope) for these curves revealed the $\mathrm{R}_{\max }$ (maximal response; highest point of each concentration-response curve) and the $\mathrm{pEC}_{50}$ (negative logarithm of the concentration that evoked $50 \%$ of the maximal response). The $\mathrm{pEC}_{50}$ is indicative of the sensitivity of the system to the drug studied.

\subsection{RNA extraction and cDNA synthesis}

Sedentary and trained animals were exsanguinated, while at rest or shortly after exercise, and mesenteric vein samples were collected. The samples were then immediately transferred to RNAlater ${ }^{\circledR}$ (cat \# AM7020 - Ambion, Inc.). In the case of exercised-sedentary and exercised-trained animals, there was an interval of approximately $10 \mathrm{~min}$ between the termination of exercise (exercised-sedentary and exercised-trained animals) and immersion in RNAlater ${ }^{\circledR}$. In accordance with the manufacturer's instructions, the samples were immersed in RNAlater ${ }^{\circledR}$ for $24 \mathrm{~h}$ at $8{ }^{\circ} \mathrm{C}$, and then kept at $-20^{\circ} \mathrm{C}$ until RNA extraction was performed.

Total RNA was extracted from these frozen mesenteric vein samples using TRIZOL (Life Technologies, Gaithersburg, MD, USA), following the manufacturer's instructions. Total RNA was quantified using a NanoDrop Spectrophotometer - 2000 (NANODROP, USA). The concentrations were adjusted, and the samples were stored at $-80^{\circ} \mathrm{C}$ until use. cDNA synthesis was carried out using High-Capacity cDNA Reverse Transcription Kits (Applied Biosystems $^{\mathrm{TM}}$, USA), following the protocol provided by the manufacturer. All cDNA was quantified using a NanoDrop Spectrophotometer - 2000 (NANODROP, USA). The concentrations were adjusted, and samples were stored at $-80^{\circ} \mathrm{C}$.

\subsection{Gene expression analysis}

All gene expression was measured by qRT-PCR on the Applied Biosystems 7500 Fast Real-Time PCR system (Applied Biosystems $^{\mathrm{TM}}$, USA), using the cycling conditions recommended by Applied Biosystems. We used the following assays: preproET-1 (ppET-1)-Assay ID: Rn00561129_m1*, ET A - Assay Id: Rn00561137_m1*, ET - Assay Id: Rn00569139_m1* and GAPDH Assay ID: Rn99999916_s1. 

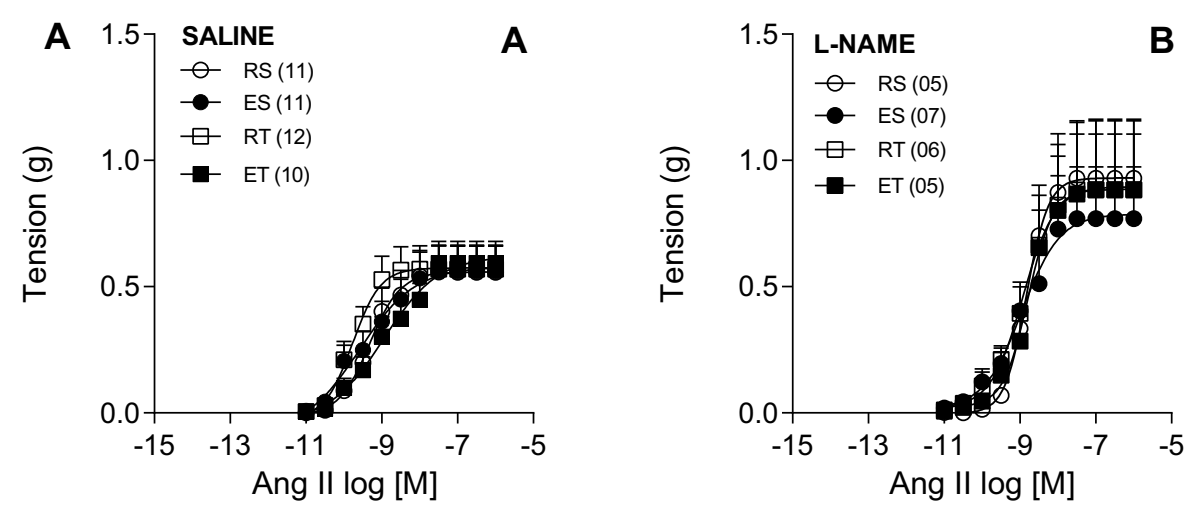

B
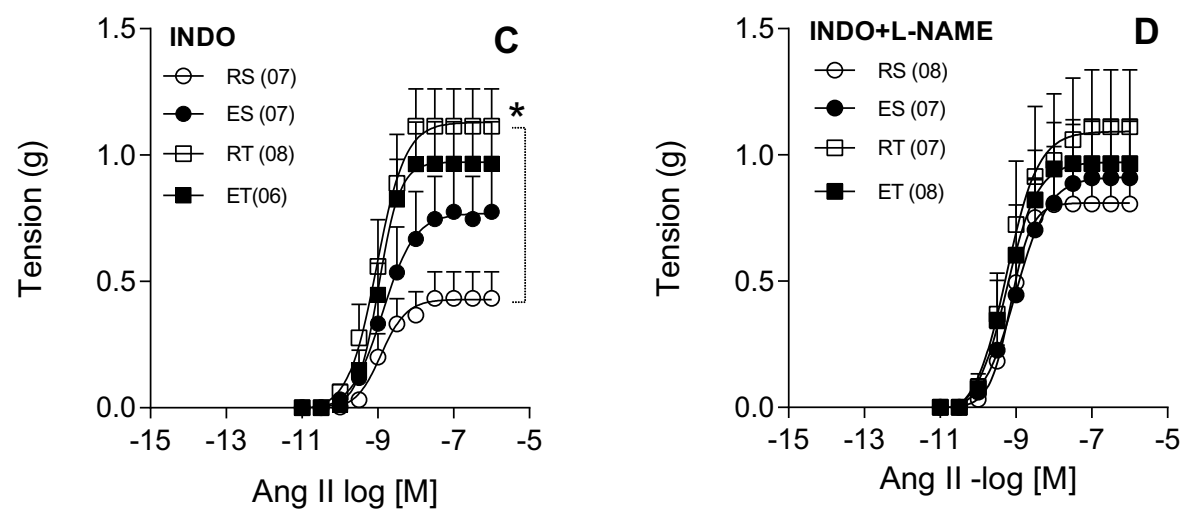

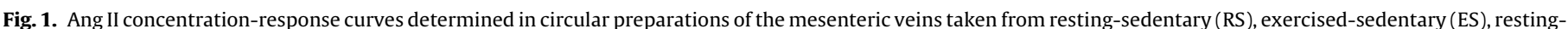

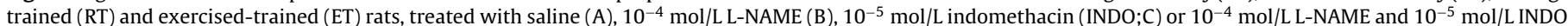

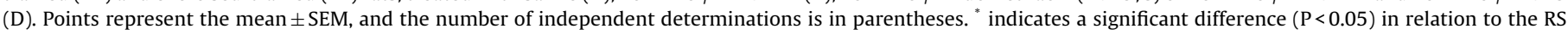
animals (two-way ANOVA followed by Tukey's post-hoc test).

The threshold values set were standardized for all assays. All reactions were performed in duplicate. Replicates with standard deviations (SD) higher than 0.5 for the cycle threshold (CT) value were repeated or excluded from the analysis.

The amplification curve of each group was determined, and the $\mathrm{CT}$ values were obtained for all genes ( $\mathrm{ppET}-1, \mathrm{ET}_{\mathrm{A}}, \mathrm{ET}_{\mathrm{B}}$ and GAPDH). We used the comparative CT method ( $\Delta \Delta \mathrm{CT}$ method), where we first calculated $\Delta \mathrm{CT}=\mathrm{CT}$ (target) $-\mathrm{CT}$ (endogenous controls) to normalize the target gene to the endogenous controls. Notably, the Relative Quantification (RQ) of ppET-1, $\mathrm{ET}_{\mathrm{A}}$ and $\mathrm{ET}_{\mathrm{B}}$ genes was calculated using the control group as a reference and using the 2- $\Delta \Delta \mathrm{CT}$ formula, which provides the percentage change, or how much more one gene is expressed in one group relative to another. All CT values were obtained using 7500 software 2.0, and these data were exported to Microsoft Excel (Microsoft, USA) to calculate $2-\Delta \mathrm{CT}$ and $\mathrm{RQ}$.

\subsection{Statistical analysis}

The data are presented as the mean $\pm S E M$. The $\mathrm{R}_{\max }$ and $\mathrm{pEC}_{50}$ values were compared by two-way ANOVA followed by Tukey's test, because one variable was exercise training and the other was exposure to a single exercise session. To ensure homoscedasticity of the data, the log of $R_{\max }$ values was used in comparisons. Values of $\mathrm{P}<0.05$ were considered statistically significant.

\section{Results}

Ang II promoted measurable contractile responses in mesenteric veins, which allowed us to obtain sigmoid concentration-response curves. The Ang II Rmax values were similar between sedentary and trained animals, whether studied at rest or after a single bout of exercise (Fig. 1A). However, the analysis of $\mathrm{pEC}_{50}$ determined in these concentration-response curves revealed a significant $(\mathrm{P}<0.05)$ interaction between "exposition to a session of exercise" and "exercise training". Thus, Ang II pEC50 values were higher in trained animals than in sedentary animals when they were studied at rest $[9.73 \pm 0.10(n=12)$ and $9.22 \pm 0.14(n=11)$, respectively]. In addition, sedentary animals exhibited an increased Ang II pEC 50 immediately after a session of exercise [from $9.22 \pm 0.14(n=11)$ to $9.53 \pm 0.26(\mathrm{n}=11)]$ while the opposite occurred in trained animals [from $9.73 \pm 0.10(n=12)$ to $9.13 \pm 0.27(n=10)$ ].

The Ang II responses obtained in all studied groups were slightly elevated in the presence of L-NAME, although no differences in $\mathrm{R}_{\max }$ or $\mathrm{pEC}_{50}$ values were observed between them (Fig. 1B). In the presence of indomethacin, the Ang II responses in exercisedsedentary animals were slightly elevated in comparison to those in resting-sedentary animals, however without significant changes in $\mathrm{R}_{\max }$ or $\mathrm{pEC}_{50}$. Nevertheless, the Ang II concentration-response curves determined in preparations taken from resting-trained animals were higher compared to those determined in preparations of resting-sedentary animals, which resulted in higher $R_{\text {max, }}$ but not $\mathrm{pEC}_{50}$ values. Interestingly, the exposition of trained animals to another bout of exercise did not evoke further elevations of $R_{\max }$ 

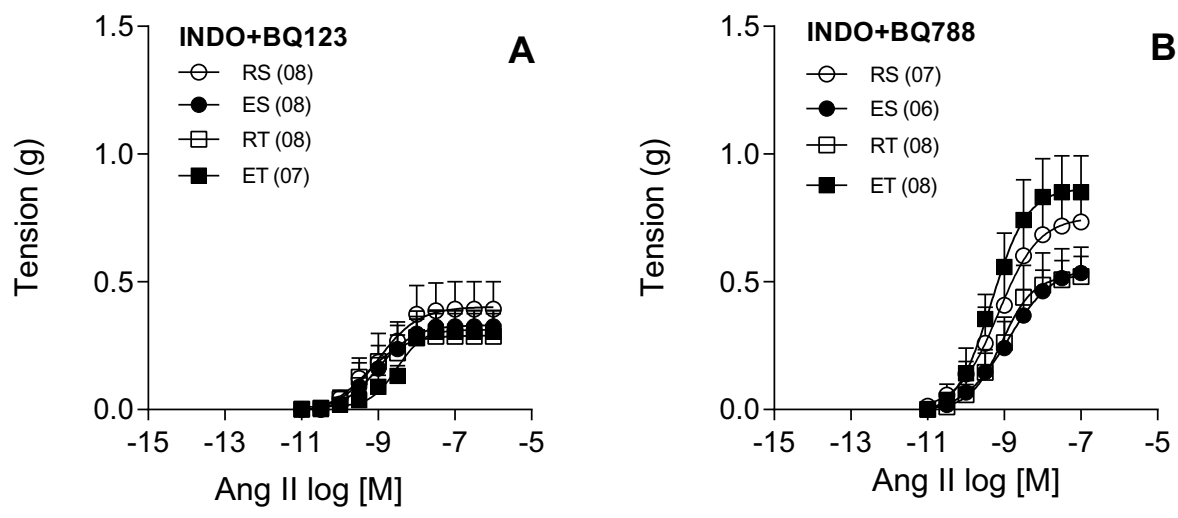

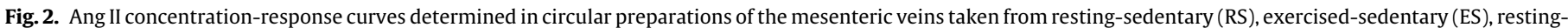

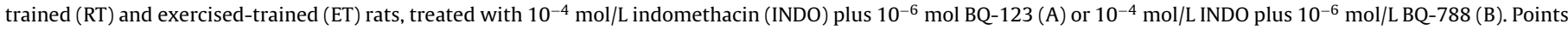
represent the mean $\pm S E M$, and the number of independent determinations is presented in parentheses.

(Fig. 1C). Furthermore, the Ang II responses determined for restingsedentary animals were increased slightly in the presence of both L-NAME and indomethacin, thereby suppressing the difference in $\mathrm{R}_{\max }$ observed in the presence of indomethacin alone (Fig. 1D).

When BQ-123 was added to the incubation together with indomethacin, the Ang II responses determined in preparations taken from exercised-sedentary, resting-trained and exercisedtrained animals were reduced at the same level of those obtained from resting-sedentary animals studied in the presence of only indomethacin. In this manner, no difference in Ang II $\mathrm{R}_{\max }$ or $\mathrm{pEC}_{50}$ were observed between groups in the presence of both indomethacin and BQ-123 (Fig. 2A). On the other hand, cotreatment with indomethacin and $\mathrm{BQ}-788$ slightly elevated the Ang II curves in mesenteric vein preparations taken from restingsedentary animals, when compared to those obtained in the presence of indomethacin alone. Thus, no differences in Ang II $R_{\max }$ or $\mathrm{pEC}_{50}$ were observed between groups in the presence of both indomethacin and BQ-788 (Fig. 2B).

ppET-1 mRNA expression in mesenteric veins was not modified either by a single bout of exercise or by exercise training (Fig. 3A). Moreover, neither exercise training nor a single bout of exercise significantly modified $\mathrm{ET}_{\mathrm{A}}$ mRNA (Fig. 3B) or $\mathrm{ET}_{\mathrm{B}}$ mRNA (Fig. 3C) expression in mesenteric veins.

Finally, the presence of PD123,319 evidenced a significant increase in Ang II $\mathrm{R}_{\max }$, without modification of pEC50, mainly in sedentary animals exposed to a single bout of exercise (Fig. 4).

\section{Discussion}

The role of active venoconstriction in venous return during exercise is still poorly understood. Some authors suggest that active venoconstriction is essential to providing the end-diastolic volume seen during exercise [11]. Others argue that it would cause a proportionally much larger elevation in resistance to flow, thereby impairing venous return $[8,12]$. Since these disagreements are sharper in venous beds belonging to musculocutaneous circulation, in a previous study we investigated the effects of exercise upon the Ang II responses in femoral veins [7]. In this study, the Ang II responses were very discreet in femoral veins. Moreover, it was observed that exposure to either acute exercise or training enables vasodilator prostanoids to start cooperating with $\mathrm{NO}$, in a redundant fashion [13], to maintain reduced Ang II responses in femoral veins. This exercise-induced adaptation in femoral veins is apparently essential to ensure an appropriate venous return, primarily during intense locomotor activity. Indeed, it may prevent an uncontrolled increase in resistance to blood flow coming from the hindlimb, even if the mechanisms related to NO fail.
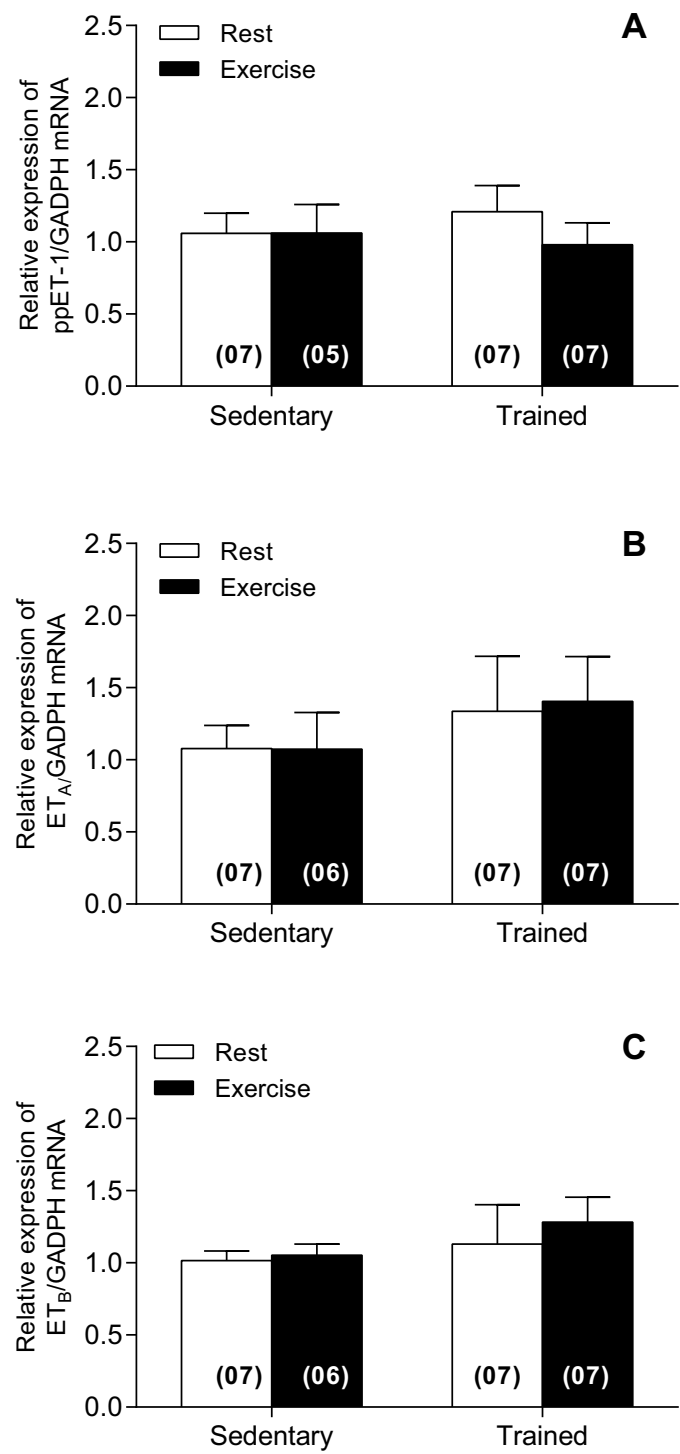

Fig. 3. Relative expression of ppET-1 (A), $\mathrm{ET}_{\mathrm{A}}(\mathrm{B})$ and $\mathrm{ET}_{\mathrm{B}}(\mathrm{C})$ mRNA detected in portal veins taken from resting-sedentary (RS), exercised-sedentary (ES), resting-trained (RT) and exercised-trained (ET) rats. Bars represent the mean \pm SEM, and the number of independent determinations is presented in parentheses. 


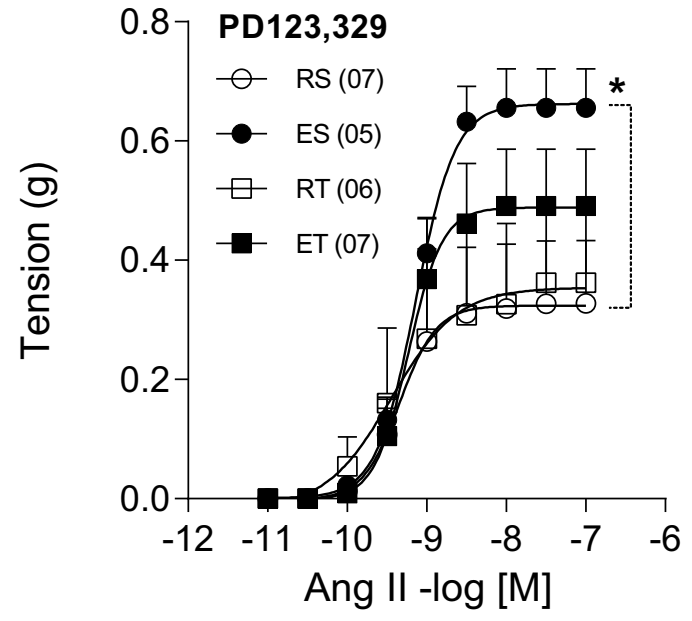

Fig. 4. Ang II concentration-response curves determined in circular preparations of femoral vein taken from resting-sedentary (RS), exercised-sedentary (ES), restingtrained (RT) and exercised-trained (ET) rats treated with $10^{-6}$ PD123,319. Points represent the mean $\pm S E M$, and the number of independent determinations is presented in parentheses. ${ }^{*}$ indicates a significant difference $(\mathrm{P}<0.05)$ in relation to the RS animals (two-way ANOVA followed by Tukey's post-hoc test).

On the other hand, there is agreement in the literature that the active venoconstriction may be involved at least partially in the venous return from splanchnic circulation during exercise. However, the local modulating mechanisms involved in vasomotor tonus regulation in the splanchnic veins is still little understood. In the present study, the Ang II responses were much higher in mesenteric veins than those previously obtained in femoral veins [7], thus permitting us to obtain sigmoidal concentrationresponse curves. Apparently, the Ang II responses in mesenteric veins must be stronger than in femoral veins in order to facilitate the blood displacement from splanchnic circulation. However, even in mesenteric venous circulation, local mediators keep the Ang II responses under control. In fact, previous studies have suggested that Ang II responses in the mesenteric venous bed are essentially modulated by NO in Wistar rats [14] or by vasodilator prostanoids in spontaneously hypertensive rats [4].

Either in arteries or in veins, local mechanisms may modulate Ang II responses during exercise and, at the same time, they may be influenced by exercise exposition. In the present study, although L-NAME slightly increased the Ang II responses in mesenteric veins taken from animals exposed or not exposed to exercise, such modifications of response were not significant. However, the presence of indomethacin elevated the Ang II responses in mesenteric veins taken from resting-trained animals, but not in those preparations obtained from resting-sedentary animals. In addition, the presence of both indomethacin plus L-NAME slightly elevated Ang II responses only in the mesenteric veins taken from resting-sedentary animals. In this manner, the Ang II responses in mesenteric veins of resting-sedentary animals were of similar magnitude with preparations taken from trained animals. Together, these data suggest that NO is able to maintain reduced Ang II responses in the mesenteric veins of sedentary animals. However, inasmuch as the animals are submitted to exercise training, vasodilator prostanoids are mobilized to act in parallel with NO in order to counterbalance the Ang II responses in their femoral veins.

The presence of vasodilator prostanoids in the femoral veins of animals exposed to exercise training may be necessary to counterbalance the influence of vasoconstrictive substances upon Ang II responses. In these preparations, the Ang II responses may have been reinforced by ET-1 released from the endothelial cells. In fact, the Ang II-induced release of ET-1 from endothelial cells has already been suggested in the literature [15-17]. Notably, the increase in
Ang II responses, evidenced by indomethacin in preparations taken from animals exposed to exercise training, were completely prevented when $\mathrm{BQ}-123$ was added to the incubation. Therefore, in these preparations, Ang II probably released ET- 1 from the endothelial cells that, in turn, reinforced the Ang II contractile responses by acting on $\mathrm{ET}_{\mathrm{A}}$ located in smooth muscle cells. This synergism may also justify, at least partially, the higher sensitivity of mesenteric veins to Ang II in resting-trained animals that was observed in experiments performed in the absence of either L-NAME or indomethacin. However, this higher sensitivity to Ang II was no longer observed in the presence of NOS or COX inhibitors, as it was probably masked by the changes in Ang II Rmax. Interestingly, the elevations in Ang II responses observed in the absence of prostanoids reached statistical significance only in trained animals. This indicates that the synergism between ET-1/ET $\mathrm{E}$ and Ang II observed in these mesenteric veins is the result of a long-term exercise adaptation. Moreover, similar patterns of Ang II responses were observed in trained animals, either at rest or after a bout of exercise, suggesting a lasting adaptation.

When BQ-788 was added to the incubation together with indomethacin, the differences in Ang II responses seen between groups also ceased to be significant. Under these conditions, the mesenteric veins of resting-sedentary animals presented Ang II responses slightly greater than those obtained in the presence of indomethacin alone. These data suggest that Ang II releases ET-1 in the mesenteric veins of resting-sedentary animals; ET- 1 which, in turn, maintains a reduced Ang II response, most likely through the $\mathrm{ET}_{\mathrm{B}}$-mediated release of NO. Indeed, the stimulation of $\mathrm{ET}_{\mathrm{B}}$ present in the endothelium may induce vasodilation through the release of NO, as well as other vasodilator substances [18-20]. On the other hand, preparations taken from animals submitted to the different exercise protocols, in the presence of both indomethacin and BQ-788, presented slightly lower Ang II responses than when in the presence of only indomethacin. This apparent reduction of Ang II was more evident in resting-trained animals. Indeed, in these preparations, the Ang II-induced responses may have been reinforced by the activation of $\mathrm{ET}_{\mathrm{B}}$. Notably, there are reports of $\mathrm{ET}_{\mathrm{B}}$-mediated vasoconstriction in several vascular beds [21-23].

The apparent increase in the participation of ET- 1 in the Ang II-induced contraction of mesenteric veins, observed in trained animals, was not accompanied by an increased expression of ppET$1, \mathrm{ET}_{\mathrm{A}}$ or $\mathrm{ET}_{\mathrm{B}}$ mRNA. This suggests that the presence of ET-1, as well as its receptors, were not modified by exercise training in the mesenteric veins. These data were unexpected since exercise training reduces the mRNA expression of ppET- 1 in femoral veins [7]. However, it is important to note that Real-time PCR evaluated gene expression but not protein synthesis. Actually, Real-time PCR was chosen to investigate the local expression of ppET-1, $\mathrm{ET}_{\mathrm{A}}$ and $\mathrm{ET}_{\mathrm{B}}$ because rat mesenteric veins are too small to employ direct methods to quantify peptides. Nevertheless, since the expression of neither ppET-1, $\mathrm{ET}_{\mathrm{A}}$ nor $\mathrm{ET}_{\mathrm{B}} \mathrm{mRNA}$ were modified by the employed exercise protocols, it is very likely that the proteins produced from these mRNAs are also present in equivalent amounts across the groups.

Since ET-1, $\mathrm{ET}_{\mathrm{A}}$ and $\mathrm{ET}_{\mathrm{B}}$ are apparently present in equivalent amounts across the groups, the observed reinforcement of the Ang II effects on preparations taken from trained animals may be a consequence of an increment of downstream signaling mechanisms activated by $\mathrm{ET}_{\mathrm{A}}$ stimulation. In this way, it was observed that exercise training enhances theET- 1 contractile responses in porcine collateral-dependent small coronary arteries, most likely via increased $\mathrm{ET}_{\mathrm{A}} / \mathrm{PKC}$-mediated $\mathrm{Ca}^{(2+)}$ sensitization $[24,25]$. On the other hand, one also cannot rule out an increase in the release of preformed ET-1, from Weibel-Palade bodies [26,27], in these animals subjected to physical training. Notably, Ang II-induced 
WPB exocytosis has already been evidenced in cultures of human endothelial cells [28].

In order to better understand the pathway by which Ang II releases the aforementioned modulating substances, mesenteric veins were also challenged in the presence of PD123,319. Indeed, since the late 1990s it has been suggested that the AT2 may release several endothelium-derived vasodilating substances and, thus, partially counterbalance its vasoconstrictor effects on AT1 [29,30]. However, in the presence of this $\mathrm{AT}_{2}$ antagonist, only preparations taken from exercised-sedentary animals presented increased Ang II responses. In disagreement with these data, Ang II responses did not increase significantly after treatment with L-NAME or indomethacin in these exercised-sedentary animals. This suggests that other relaxing substances beyond NO or prostanoids may perhaps be released by $\mathrm{AT}_{2}$ activation, therefore contributing to the modulation of Ang II responses in these preparations. On the other hand, the mobilization of vasodilator prostanoids that occurs in preparations of trained animals - the focus of the present study - does not appear to involve $\mathrm{AT}_{2}$. Therefore, this Ang II-induced prostanoid mobilization may possibly occur through $\mathrm{AT}_{1}$ stimulation. In this regard, there is evidence that stimulation of $\mathrm{AT}_{1}$ present in either the endothelium or subendothelial tissues may release vasodilator prostanoids [31]. Nevertheless, further studies are required to identify the receptor involved in this modulation.

The present study would be improved if experiments were also performed on preparations without endothelium, in order to confirm the endothelial origin of substances that modulate Ang II responses. However, it was not possible to remove the endothelium from the mesenteric veins due to their small size and fragility. Moreover, the effectiveness of the endothelial removal could not be ascertained because, like the femoral veins, these preparations do not exhibit enough stable precontractions to study their acetylcholine-induced relaxation.

Finally, the presented data suggest that exercise training modifies the secretor capacity of the endothelium in the mesenteric veins studied, but the way in which it does so remains uncertain. The studies suggesting exercise-induced modifications in endothelial function point to shear stress as the main factor that triggers such adaptations. In fact, shear stress may induce the production of nitric oxide (NO) [32-34] and/or prostanoids [35,36]. Shear stress also may increase or decrease ET-1 production, depending on its intensity and duration [37,38]. With this in mind, regular elevations of shear stress during the exercise training period may have induced the modifications observed in the local modulating mechanisms in the present study. Coincidentally, it has been demonstrated that exercise-induced circulatory changes may increase shear stress upon the endothelial layer of veins [39]. However, it is important to make clear that this is only the most widely accepted explanation for this phenomenon, which does not exclude the need to investigate other mechanisms.

\section{Conclusions}

In conclusion, the present study suggests that exercise training mobilizes ET-1 to reinforce the Ang II-induced responses mainly through $\mathrm{ET}_{\mathrm{A}}$ activation. On the other hand, vasodilator prostanoids are mobilized to act in parallel with NO in order to counterbalance the Ang II responses that have been potentiated by ET- 1 in the mesenteric veins of these trained animals.

\section{Acknowledgments}

This study was supported by Fundação de Amparo à Pesquisa do Estado de São Paulo (FAPESP; process no. 09/09788-4). The authors thank Mr. Alisson Douglas Ventura Neves and Priscila Ramos de Oliveira (Laboratory of Pharmacology, Faculty of Medicine of Marília, São Paulo, Brazil) for technical assistance.

\section{References}

[1] S. Maeda, M. Iemitsu, S. Jesmin, T. Miyauchi, Acute exercise causes an enhancement of tissue renin-angiotensin system in the kidney in rats, Acta Physiol. Scand. 185 (1) (2005) 79-86.

[2] Z. Barrett-O'Keefe, M.A. Witman, J. McDaniel, A.S. Fjeldstad, J.D. Trinity, S.J. Ives, J.D. Conklin, V. Reese, S. Runnels, D.E. Morgan, M. Sander, R.S. Richardson, D.W. Wray, Angiotensin II potentiates alpha-adrenergic vasoconstriction in the elderly, Clin. Sci. (Lond.) 124 (6) (2013) 413-422.

[3] C. Dasgupta, L. Zhang, Angiotensin II receptors and drug discovery in cardiovascular disease, Drug Discov. Today 16 (1-2)(2011) 22-34.

[4] R.A. Loiola, L. Fernandes, R. Eichler, C. Passaglia Rde, Z.B. Fortes, M.H. de Carvalho, Vascular mechanisms involved in angiotensin II-induced venoconstriction in hypertensive rats, Peptides 32 (10)(2011) 2116-2121.

[5] S.M. Sartoretto, R. Santos-Eichler, A.T.R. de Cassia, M.H. Carvalho, E.H. Akamine, Z.B. Fortes, Role of nitric oxide and endothelin in endothelial maintenance of vasoconstrictor responses in aortas of diabetic female rats, J. Diabetes 5 (2) (2013) 197-206.

[6] A.B. Chies, P. de Souza Rossignoli, Exercise increases the phenylephrine effects in isolated portal vein of trained rats, Vasc. Pharmacol. 51 (2-3) (2009) $125-132$.

[7] A.B. Chies, P.e.S. Rossignoli, R.e.F. Baptista, R.W. de Lábio, S.L. Payão, Exercise reduces angiotensin II responses in rat femoral veins, Peptides 44 (2013) 47-54.

[8] L.B. Rowell, Human Cardiovascular Control, Oxford University Press, New York, 1993.

[9] R.M. Melo, E. Martinho, Jr., L.C. Michelini, Training-induced, pressure-lowering effect in SHR: wide effects on circulatory profile of exercised and nonexercised muscles, Hypertension 42 (4) (2003) 851-857.

[10] A.S. Martins, A. Crescenzi, J.E. Stern, S. Bordin, L.C. Michelini, Hypertension and exercise training differentially affect oxytocin and oxytocin receptor expression in the brain, Hypertension 46 (4) (2005) 1004-1009.

[11] C.F. Rothe, Point: active venoconstriction is/is not important in maintaining or raising end-diastolic volume and stroke volume during exercise and orthostasis, J. Appl. Physiol. 101 (4) (2006) 1262-1264 (1985).

[12] R. Hainsworth, M.J. Drinkhill, Counterpoint: active venoconstriction is not important in maintaining or raising end-diastolic volume and stroke volume during exercise and orthostasis, J. Appl. Physiol. 101 (4) (2006) 1264-1265 (1985).

[13] D. Merkus, D.B. Haitsma, T.Y. Fung, Y.J. Assen, P.D. Verdouw, D.J. Duncker, Coronary blood flow regulation in exercising swine involves parallel rather than redundant vasodilator pathways, Am. J. Physiol. Heart Circ. Physiol. 285 (1) (2003) H424-33.

[14] L. Fernandes, R.A. Loiola, R.C. Tostes, D. Nigro, Z.B. Fortes, M.H. de Carvalho, Angiotensin II-induced venoconstriction involves both AT1 and AT2 receptors and is counterbalanced by nitric oxide, Peptides 26 (12) (2005) 2458-2463.

[15] L. Yu, G. Yang, X. Weng, P. Liang, L. Li, J. Li, Z. Fan, W. Tian, X. Wu, H. Xu, M Fang, Y. Ji, Y. Li, Q. Chen, Y. Xu, Histone methyltransferase SET1 mediates angiotensin II-induced endothelin-1 transcription and cardiac hypertrophy in mice, Arterioscler. Thromb. Vasc. Biol. 35 (5) (2015) 1207-1217.

[16] G.K. Oriji, H.R. Keiser, Protein kinase C mediates angiotensin II-induced contractions and the release of endothelin and prostacyclin in rat aortic rings, Prostaglandins Leukot. Essent. Fatty Acids 57 (2) (1997) 135-141.

[17] G.K. Oriji, Angiotensin II-induced ET and PGI2 release in rat aortic endothelial cells is mediated by PKC, Prostaglandins Leukot. Essent. Fatty Acids 61 (2) (1999) 113-117.

[18] A. Just, A.J. Olson, J.R. Falck, W.J. Arendshorst, NO and NO-independent mechanisms mediate ETB receptor buffering of ET-1-induced renal vasoconstriction in the rat, Am. J. Physiol. Regul. Integr. Comp. Physiol. 288 (5) (2005) R1168-R1177.

[19] M. Iglarz, P. Steiner, D. Wanner, M. Rey, P. Hess, M. Clozel, Vascular effects of endothelin receptor antagonists depends on their selectivity for ETA versus ETB receptors and on the functionality of endothelial ETB receptors, J. Cardiovasc. Pharmacol. 66 (4) (2015) 332-337.

[20] J.J. Maguire, A.P. Davenport, Endothelin receptors and their antagonists, Semin. Nephrol. 35 (2) (2015) 125-136.

[21] K.M. McCulloch, C.C. Docherty, I. Morecroft, M.R. MacLean, EndothelinB receptor-mediated contraction in human pulmonary resistance arteries, $\mathrm{Br}$. J. Pharmacol. 119 (6) (1996) 1125-1130.

[22] S.M. Black, E. Mata-Greenwood, R.W. Dettman, B. Ovadia, R.K. Fitzgerald, O. Reinhartz, S. Thelitz, R.H. Steinhorn, R. Gerrets, K. Hendricks-Munoz, G.A. Ross, J.M. Bekker, M.J. Johengen, J.R. Fineman, Emergence of smooth muscle cell endothelin B-mediated vasoconstriction in lambs with experimental congenital heart disease and increased pulmonary blood flow, Circulation 108 (13) (2003) 1646-1654.

[23] K.M. McCulloch, M.R. MacLean, EndothelinB receptor-mediated contraction of human and rat pulmonary resistance arteries and the effect of pulmonary hypertension on endothelin responses in the rat, J. Cardiovasc. Pharmacol. 26 (Suppl. 3) (1995) S169-S176

[24] J.C. Robles, M. Sturek, J.L. Parker, C.L. Heaps, Ca2+ sensitization and PKC contribute to exercise training-enhanced contractility in porcine 
collateral-dependent coronary arteries, Am. J. Physiol. Heart Circ. Physiol. 300 (4) (2011) H1201-H1209.

[25] J.C. Robles, C.L. Heaps, Adaptations of the endothelin system after exercise training in a porcine model of ischemic heart disease, Microcirculation 22 (1) (2015) 68-78

[26] T. Ozaka, Y. Doi, K. Kayashima, S. Fujimoto, Weibel-Palade bodies as a storage site of calcitonin gene-related peptide and endothelin-1 in blood vessels of the rat carotid body, Anat. Rec. 247 (3) (1997) 388-394.

[27] M.G. Rondaij, R. Bierings, A. Kragt, J.A. van Mourik, J. Voorberg, Dynamics and plasticity of Weibel-Palade bodies in endothelial cells, Arterioscler. Thromb. Vasc. Biol. 26 (5) (2006) 1002-1007.

[28] X. Ge, B. Low, M. Liang, J. Fu, Angiotensin II directly triggers endothelial exocytosis via protein kinase C-dependent protein kinase D2 activation, J. Pharmacol. Sci. 105 (2) (2007) 168-176.

[29] R.M. Carey, Cardiovascular and renal regulation by the angiotensin type 2 receptor: the AT2 receptor comes of age, Hypertension 45 (5) (2005) 840-844.

[30] L.C. Matavelli, H.M. Siragy, AT2 receptor activities and pathophysiological implications, J. Cardiovasc. Pharmacol. 65 (3) (2015) 226-232.

[31] T. Kimura, N. Toda, Y. Noda, T. Okamura, Mechanisms of relaxation induced by angiotensin II in isolated canine and human uterine arteries, J. Cardiovasc. Pharmacol. 37 (5) (2001) 585-595.

[32] M. Uematsu, Y. Ohara, J.P. Navas, K. Nishida, T.J. Murphy, R.W. Alexander, R.M. Nerem, D.G. Harrison, Regulation of endothelial cell nitric oxide synthase mRNA expression by shear stress, Am. J. Physiol. 269 (6 Pt 1) (1995) C1371-C1378.

[33] Z. Xiao, Z. Zhang, V. Ranjan, S.L. Diamond, Shear stress induction of the endothelial nitric oxide synthase gene is calcium-dependent but not calcium-activated, J. Cell. Physiol. 171 (2)(1997) 205-211.
[34] M. Cattaruzza, T.J. Guzik, W. Slodowski, A. Pelvan, J. Becker, M. Halle, A.B. Buchwald, K.M. Channon, M. Hecker, Shear stress insensitivity of endothelial nitric oxide synthase expression as a genetic risk factor for coronary heart disease, Circ. Res. 95 (8) (2004) 841-847.

[35] H. Inoue, Y. Taba, Y. Miwa, C. Yokota, M. Miyagi, T. Sasaguri, Transcriptional and posttranscriptional regulation of cyclooxygenase-2 expression by fluid shear stress in vascular endothelial cells, Arterioscler. Thromb. Vasc. Biol. 22 (9) (2002) 1415-1420.

[36] L. Di Francesco, L. Totani, M. Dovizio, A. Piccoli, A. Di Francesco, T. Salvatore, A Pandolfi, V. Evangelista, R.A. Dercho, F. Seta, P. Patrignani, Induction of prostacyclin by steady laminar shear stress suppresses tumor necrosis factor-alpha biosynthesis via heme oxygenase- 1 in human endothelial cells, Circ. Res. 104 (4) (2009) 506-513.

[37] A. Ishibazawa, T. Nagaoka, T. Takahashi, K. Yamamoto, A. Kamiya, J. Ando, A Yoshida, Effects of shear stress on the gene expressions of endothelial nitric oxide synthase, endothelin-1, and thrombomodulin in human retinal microvascular endothelial cells, Invest. Ophthalmol. Vis. Sci. 52 (11) (2011) 8496-8504.

[38] M.J. Kuchan, J.A. Frangos, Shear stress regulates endothelin-1 release via protein kinase C and cGMP in cultured endothelial cells, Am. J. Physiol. 264 (1 Pt 2) (1993) H150-H156.

[39] C.P. Cheng, R.J. Herfkens, C.A. Taylor, Inferior vena caval hemodynamics quantified in vivo at rest and during cycling exercise using magnetic resonance imaging, Am. J. Physiol. Heart Circ. Physiol. 284 (4) (2003) H1161-H1167. 